\title{
THE LIGAMENT OF COCHLODESMA PRAETENUE (PULTENEY)
}

\author{
By J. A. Allen \\ Dove Marine Laboratory, Cullercoats
}

(Text-fig. I)

In a recent paper (Allen, I958) the ligament of Cochlodesma praetenue (Pulteney) was shown to have unusual features, the significance of which was not appreciated at that time. Examination of its structure shows that a further description is necessary.

Studies by Owen, Trueman \& Yonge (1953), Owen (1958, 1959), and Yonge (1953, I957) have made clear the basic structure of the ligament of the adult bivalve. Primarily the ligament is composed of an inner layer covered by the anterior and posterior outer layers and the periostracum. The inner layer is secreted by the epithelium of the mantle isthmus, the outer layers are secreted by the outer surface of the outer mantle fold within the depths of the mantle embayments at either end of the mantle isthmus, and the periostracum is secreted by the inner surface of the outer mantle fold. This primary ligament may be secondarily extended anteriorly and/or posteriorly by fusion of the mantle margins and may involve (I) extension by periostracum, or (2) extension by fusion layer.

The ligament of $C$. praetenue, although much modified, is opisthodetic, i.e. the point of minimal growth is anterior (Owen, I959; Allen, 1960). The primary ligament is secondarily extended anteriorly and posteriorly by fused periostracum and fusion layer. These secondary layers can be seen externally and are remarkable for the unusual paired lateral extensions of the fusion layer which follow the line of the umbonal ridge (Fig. I). The primary ligament is internal. The ligament is best described by analysis of its various parts.

The inner layer lies below the umbo. It is held between a pair of spoonshaped extensions of the pronounced internal ridges of each shell valve (see Allen, 1958, fig. 2). The lateral faces of the inner layer attached to the spoonshaped extensions are concave, while the free ventral edge is grooved in the sagittal plane. Growth lines show that most of the growth takes place ventrally and posteriorly (Fig. I C).

The posterior outer layer is applied to the postero-dorsal sides of the inner layer. It is wedge-shaped and all growth is posterior. The growth lines are continuous with those of the inner layer. The lateral faces are slightly convex. 
The posterior fusion layer covers the dorsal side of the posterior outer layer and extends to a point close to the anterior limit of the posterior adductor muscle.

The anterior outer layer is remarkable for its scroll-like form. It extends a short distance anterior to the posterior outer layer and fans out forming a pair of lateral wings. From the posterior edge of the wings a thin sheet of this

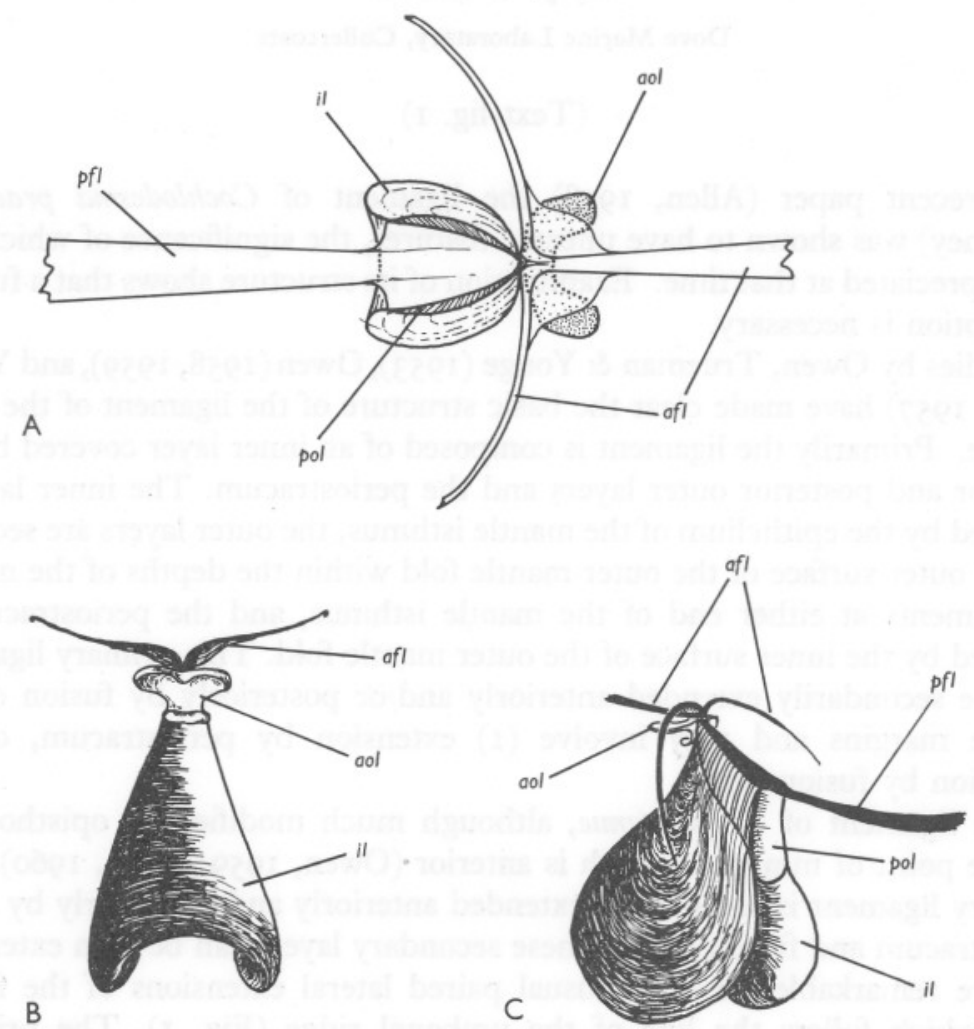

Fig. I. Semi-diagrammatic views of the ligament of Cochlodesma praetenue as seen (A) dorsally, (B) anteriorly and (C) postero-laterally. afl, anterior fusion layer, aol, anterior outer layer, $i l$, inner layer, $p f l$, posterior fusion layer, pol, posterior outer layer. The covering periostracum is not shown.

layer extends ventrally overlapping the inner layer to a slight extent (Fig. I B, C). This gives the erroneous impression that the anterior outer layer is merely a continuation of the inner layer (see Allen, I958, p. 98).

The anterior fusion layer is also unusual. It extends from just posterior to the anterior adductor muscle to the posterior limit of the anterior outer layer where it divides into two lateral forks that follow the line of the umbonal ridge. The angle between each fork and the sagittal part has a thin covering 
of fusion layer, which is separate from the underlying wings of the anterior outer layer (Fig. I A, B). A fold of epithelium extends between the two layers.

The fused periostracum covers the ligament and extends slightly beyond the anterior and posterior limits of the fusion layer.

It is clear that this ligament, although unusual, does not differ basically in its constitution from any other opisthodetic ligament. Posterior fusion layer, posterior outer layer and inner layer are normal. It is the lateral extensions of the anterior outer layer and anterior fusion layer that are atypical. It seems likely that these are formed by extension, lateral folding and fusion of the outer mantle edge in the depths of the anterior embayment.

\section{SUMMARY}

The ligament of Cochlodesma praetenue is described. Although unusual in form, it does not differ basically from other opisthodetic ligaments.

\section{REFERENCES}

Allen, J. A., I958. Observations on Cochlodesma praetenue (Pulteney) (Eulamellibranchia). F. mar. biol. Ass. U.K., Vol. 37, pp. 97-II2. 1960. The ligament of the Lucinacea (Eulamellibranchia) Quart. F. micr. Sci., Vol. IOI, pp. 25-36.

OwEN, G., I958. Shell form, pallial attachment and the ligament in the Bivalvia. Proc. zool. Soc. Lond., Vol. 131, pp. 637-48.

OwEN, G., I959. Observations on the Solenacea with reasons for excluding the family Glaucomyidae. Phil. Trans. B., Vol. 242, pp. 59-97.

Owen, G., Trueman, E. R. \& Yonge, C. M., 1953. The ligament in the Lamellibranchia. Nature, Lond., Vol. I7I, p. 73.

Yonge, C. M., 1953. Form and habit in Pinna carnea Gmelin. Phil. Trans. B, Vol. 237, pp. 335-74.

1957. Mantle fusion in the Lamellibranchia. Pubbl. Staz. zool. Napoli, Vol. 29, pp. I5I-7I. 